\title{
Nacionalidade e cidadania pelo acesso à terra no século XIX: reflexões a partir das variações de escalas e da História Global
}

\author{
Nationality and citizenship for access to land in the nineteenth century: reflections on \\ scale variation and Global History \\ Flávia Paula Darossi \\ https://orcid.org/0000-0002-5044-4609 \\ Universidade Federal de Santa Catarina
}

\begin{abstract}
Resumo: $O$ artigo discute os principais enunciados do que se convencionou chamar como História Global, campo de estudos em curso desde a década de 1990 interessado na reformulação teórico-epistemológica da História. Repercutindo a nova globalização acelerada desde a década de 1970, a História Global tem embasado sua crítica ao eurocentrismo e ao nacionalismo metodológico presentes na produção historiográfica geral, em favor do retorno à história explicativa sobre a multiplicidade dos grandes processos históricos e a valorização de conexões transnacionais a partir de vastos espaços e longas durações. Meus objetivos são problematizar alguns dos limites desta pretensa novidade teórico-metodológica, contrapondo-a a proposição da Micro-História sobre a variação das escalas de análise, e considerar algumas de suas reais contribuições ao debate historiográfico. Para desenvolvê-los, aplicarei a discussão às questões relacionais da nacionalidade, cidadania, imigração e acesso à terra no Brasil durante o século XIX. Fá-lo-ei a partir de uma única amostra documental, um abaixoassinado de 1886 de trabalhadores rurais do município de Tubarão, província de Santa Catarina. Problematizarei a representatividade de uma fonte específica para a construção de narrativas históricas acerca de temas de experiência global.
\end{abstract}

Palavras-chave: História Global. Micro-História. Propriedade territorial. Cidadania.

ABSTRACT: The article discusses the main statements of what is conventionally called Global History, a field of studies in progress since the 1990s interested in the theoretical and epistemological reformulation of History. Repercussing the accelerated new globalization since the 1970s, Global History has based its criticism on Eurocentrism and methodological nationalism present in the general historiographical production, in favor of a return to the explanatory history about the multiplicity of the great historical processes and the valorization of transnational connections from vast spaces and long durations. My goals are to problematize some of the limits of this alleged theoreticalmethodological novelty, opposing it to Micro-History's proposition about the variation of the analysis scales, and to consider some of its real contributions to the historiographical debate. To develop them, I will apply the discussion to the relational issues of nationality, citizenship, immigration, and land access in Brazil during the nineteenth century. I will do so from a single documentary source, an 1886 petition from rural workers in the city of Tubarão, Santa Catarina province. I will problematize the representativeness of a specific source for the construction of historical narratives about themes of global experience.

Keywords: Global History. Micro-History. Land property. Citizenship.

Esta obra está licenciada sob uma Creative Commons - Atribuição 4.0 Internacional 


\section{Os sentidos da História Global}

O campo da História Global não tem definição unânime. Para a historiadora estadunidense Pamela Crossley, no livro What is global history?, de 2008, a proposta da História Global é "contar uma história sem um centro". Seu recurso não seria um texto ou um conceito analítico, mas antes "um fiandeiro de contexto que em determinado momento pode ordenar eventos e estatísticas a partir da perspectiva de um material ou dispositivo (tais como o estudo da seda de Shelagh Vainker...), ou de um conceito comportamental (tais como o de Michel Focault sobre a sexualidade...)" (CROSSLEY, 2015, p. 05). A História Global pressupõe a "reformulação dos próprios objetos de pesquisa, a formulação de novas perguntas e o questionamento de certos dogmas da disciplina, empenhando-se em pensar no globo" (CROSSLEY, 2015, p. 20). Tal perspectiva tornou-se fundamental pelos efeitos da globalização e da "nova era tecnológica": o mundo tornava-se progressivamente mais populoso, conectado com o encurtamento das distâncias e a aceleração do tempo histórico.

De acordo com a autora, é consensual no debate historiográfico Global a rejeição ou a relativização de unidades de análise baseadas no eurocentrismo e no nacionalismo metodológico. Valorizam-se estudos que, de um lado, descentralizem a Europa e o Ocidente e os desnaturalizem enquanto condicionantes de conceitos como "progresso", "modernidade" e "industrialização" e que, de outro, "desparoquializem" e integrem fatos locais e regiões em contextos mais amplos. Outro dogma da disciplina é a cronologia, convencionalmente representada por um tempo social uniforme, neutro, linear e progressivo definido pela experiência europeia (classificado pelos períodos antigo, clássico, feudal, moderno, etc.).

Crossley explica que a História Global objetiva pautar a análise histórica a conexões transnacionais, na mobilidade e na troca simbólica entre sociedades e nos reagrupamentos entre diferentes culturas e espaços. O "mundo" passa a ser a categoria analítica histórico-social geral, baseada na sincronicidade das relações humanas. Metodologicamente, esta abordagem é facilitada por poder prescindir de fontes primárias e basear as pesquisas em trabalhos de outros historiadores, fazendo comparações, observando padrões amplos e "propondo maneiras de compreender" a natureza e a história humana. A perspectiva dos historiadores globais "deve ser ampla, em termos espaciais e cronológicos", sendo "só desta forma possível identificar divergências, convergências e a própria constituição desses sistemas" (CROSSLEY, 2015, p. 113).

Para o historiador alemão Sebastian Conrad, em livro de 2016, homônimo ao de Crossley, uma definição preliminar e bastante ampla da História Global pode descrevêla como uma forma de análise histórica na qual fenômenos, eventos e processos são colocados em contextos globais (CONRAD, 2016, p. 05). Seria tanto um objeto de estudo, quanto uma maneira particular de olhar a História, isto é, um processo e uma perspectiva, um assunto e uma metodologia, instrumento heurístico que pode viabilizar novas questões e respostas gerais, diferentes das criadas por outras abordagens (CONRAD, 2016, p. 09).

O autor identificou três reações ao "desafio do global", a saber, a História Global como a história de tudo - tudo o que aconteceu na terra é um ingrediente legítimo -; a história de trocas e conexões - o fio condutor que une esse tipo de estudos é a visão geral de que nenhuma sociedade, nação ou civilização existe isoladamente -; e a história baseada no conceito de integração - esta, a maior promessa aos historiadores 
globais que pretendem ir além dos gestos simbólicos em direção à conectividade (CONRAD, 2016, p. 06). O componente da História Global é aprimorado quando os historiadores orientam seus estudos com casos semelhantes e incluem livros sobre assuntos relacionados de outras partes do mundo em suas bibliografias, visto que

\begin{abstract}
Não existe limite para a gama de tópicos que podem ser estudados dessa perspectiva - de pessoas em movimento a circular ideias e negociar através de distâncias. $\mathrm{O}$ alcance das redes e conexões pode variar e não precisa ser planetário. Tudo depende do assunto e das questões perguntadas [...] A interconectividade do mundo, que pode ser rastreada ao longo de séculos, é o ponto de partida para a pesquisa histórica global. (CONRAD, 2016, p. 09) Tradução da autora1.
\end{abstract}

Além de tomarem conexões globais como objeto de pesquisas, diferentemente, outros historiadores situam casos particulares em contextos globais, procurando explicar as contingências e os processos no nível terreno da atividade humana dentro das estruturas que são ao mesmo tempo produto e condição dessa atividade (CONRAD, 2016, p. 10). Nesta leitura, o global torna-se a referência para qualquer compreensão do passado, e tal contextualização não se restringe ao passado mais recente, pode enfocar longas durações.

Como Crossley, Conrad atribuiu a pertinência da "virada global" à globalização que os séculos XX e XXI experienciaram. Segundo ele, à medida que o mundo evoluiu cada vez mais para uma única entidade política, econômica e cultural, os vínculos casuais no nível global se tornaram mais fortes, sendo que, como resultado da proliferação e da perpetuação desses vínculos, os eventos locais são cada vez mais moldados por esse contato global, podendo ser entendidos estruturalmente (CONRAD, 2016, p. 11).

Em relação à disciplina História Global do Trabalho, o historiador holandês Marcel Van der Linden explicou que a mesma "focaliza o estudo transnacional e mesmo transcontinental das relações de trabalho e dos movimentos sociais de trabalhadores no sentido mais amplo da palavra". O sentido atribuído à transnacional se refere a "situar, no contexto mais amplo de todos os processos históricos, não importa quão 'pequenos' em comparação com outros em outras partes, o estudo de processos de interação ou a combinação de ambos". Para fins de comparação, não haveria limites em relação à perspectiva temporal: estudos que recuassem ainda mais no tempo não deveriam ser excluídos (VAN DER LINDEN, 2009, p. 18).

Em geral, existe grande variedade de perspectivas historiográficas que circundam a definição de História Global pela defesa da superação do eurocentrismo e do nacionalismo metodológico, como as histórias transnacional, conectada, cruzada, mundial, comparada, relacional. Todavia, muitas destas abordagens remontam a períodos anteriores à inflexão historiográfica global, haja vista a história de longa duração de Fernand Braudel, a história comparada de Marc Bloch, a teoria do SistemaMundo de Immanuel Wallerstein, os estudos subalternos, pós-coloniais e de gênero, a própria Micro-História, como veremos adiante, etc.

Em texto de 2011, Introduction: Space and Scale in Transnational History, Jacques Revel, Bernhard Stuck e Kate Ferris observaram que o fato de que a

\footnotetext{
${ }^{1}$ Do original: "There is no limit to the range of topics that can be studied from such a perspective - from people on the move to circulating ideas and trade across distance. The reach of the networks and connections may vary and does not have to be planetary. Everything depends on the subject matter and the questions asked. [...] The interconnectedness of the world, which can be traced back over centuries, is the starting point for global historical research".
} 
globalização e o transnacionalismo estejam inter-relacionados, não significa que a História Global e a História Transnacional sejam sinônimos. Diferentemente, História Global é só uma das muitas estruturas espaciais, que não pode ser exercida sem uma perspectiva transnacional; já a História Transnacional pode ser exercida em uma escala sub-mundial ou regional (STUCK, FERRIS, KATE \& REVEL, 2011, p. 574). Eles defendem que sejam instrumentalizadas as ferramentas conectivas e comparativas da História Transnacional de modo que as pesquisas desenvolvam e enfatizem a interação e a circulação social de ideias, povos, instituições e tecnologias através de fronteiras nacionais e a influência mútua entre diferentes estados e sociedades; tratando-se de uma perspectiva de estudo que não pretende ser método específico, diferente da História Global. Os autores reconheceram que a História Transnacional pode não ser nova, mas que a produção quantitativa de publicações com "transnacional" no título atingiu um nível sem precedentes ao longo dos últimos anos. A mudança que está ocorrendo, de acordo com os autores, é que apesar de sempre ter havido histórias transnacionais implícitas, atualmente tornaram-se explícitas.

Por outro lado, em 2017, o historiador diretor do Laboratório de História Global da Universidade de Princeton, Jeremy Adelman, considerou os termos e problemas da História Global no ensaio What is global history now?, no qual afirmou que esta virada historiográfica foi uma "viagem curta" porque "o poder do lugar nunca foi embora" (ADELMAN, 2017, s.p.). Ele procurou desconstruir o argumento de historiadores como Crossley e Conrad, que justificam a legitimidade da História Global pelo fenômeno da globalização e da "perpetuação" das conexões globais, julgando-a pela atual conjuntura de transformação política internacional marcada pela ascensão crescente de governos de extrema-direita, com discursos de cunho nacionalista e antiglobalização. Com base neste argumento, torna-se cada vez mais difícil o reconhecimento do que Conrad definiu como "uma única entidade política, econômica e cultural" global.

Ademais, outros fatores desta inflexão foram apontados por Adelman, como a tentativa de reformulação pública da disciplina, após anos de queda de matrículas, cursos em declínio e um mercado de trabalho desanimador para doutores em História, em que muitos projetaram a História Global como um elixir, uma maneira de voltar à relevância pública. Mais do que isso, o autor avalia ser a História Global outra invenção anglosférica para integrar o outro em uma narrativa cosmopolita, "em nossos termos, em nossas línguas", como a economia mundial em geral. A História Global preferiu uma escala que refletisse seus próprios anseios cosmopolitas (ADELMAN, 2017, s.p.). O autor faz um apelo para que a disciplina não destaque somente os benefícios da globalização, mas também suas consequências negativas para as populações que integram o globo.

\section{O princípio micro-histórico da variação das escalas de análise}

Apesar de haver circunscrito minha reflexão em um número pequeno de estudos, é possível problematizar alguns limites da formulação teórica básica do que se convencionou chamar de História Global, dada a significativa convergência entre muitos dos seus pressupostos teórico-epistemológicos e dos apresentados pelo movimento anterior da Micro-História, principalmente quanto a variação das escalas de análise.

O historiador francês Jacques Revel afirmou no livro Jogos de escalas: a experiência da Microanálise, de 1996, que o princípio de variação das escalas de análise parte inicialmente do enfoque em experiências localizadas e singulares para, em 
seguida, exercitar a "contextualização múltipla" destas vivências, produzindo efeitos de conhecimento estrategicamente condicionados pela variação da objetiva. A partir da relação dialética entre micro e macro escalas pode-se compreender as diversas formas pelas quais os grandes processos históricos são enquadrados no vivido e, simultaneamente, como estas experiências podem ser representadas pelos historiadores em grandes processos históricos. Observemos como Revel procurou conciliar o sentido desta variação à produção histórica:

Cada ato histórico participa, de maneira próxima ou distante, de processos - e, portanto, se inscreve em contextos - de dimensões e níveis variáveis, do mais local ao mais global. Não existe, portanto, hiato, menos ainda, oposição, entre história local e história global. O que a experiência de um indivíduo, de um grupo, de um espaço permite perceber é uma modulação particular da História Global. (REVEL, 1998, p. 28)

O autor instrumentaliza os conceitos de "escala" e "contexto" juntamente ao de "processo" para articular os diferentes estratos folheados das dimensões de espaço e tempo sociais que compõem a experiência humana. Não existe divergência entre local e global, se considerarmos que são escalas essencialmente complementares: "a dimensão 'micro' não goza, neste sentido, de nenhum privilégio especial. É o princípio da variação que conta, não a escolha de uma escala em particular" (REVEL, 1998, p. 20).

O método da alternância da lente sobre o objeto é sintomático da possibilidade de a Micro-História também produzir "histórias globais", no sentido de o historiador fazêlo pela projeção da lente macro. Ao revisarmos as definições metodológicas de Crossley, Conrad e Van der Linden acerca da História Global - como "fiandeiro de contexto", "fenômenos e eventos colocados em contextos globais", "no contexto mais amplo" -, com a definição de "contextualização múltipla" preconizada por Revel, percebemos a convergência entre ambas as perspectivas. Todavia, essa convergência metodológica existe atrelada a diferenças que não podem ser negligenciadas, uma delas, trata da ampliação do tempo à análise.

Na década de 1980, a proposta da Micro-História baseou-se na crítica à história quantitativa de longa duração, em favor da complexificação da análise com o uso intensivo de fontes primárias, que favoreciam o maior conhecimento sobre experiências individuais e de grupos. À esta abordagem interessava acessar as vivências e a relação social entre pessoas, fenômenos e eventos, com o potencial heurístico de apresentar inúmeras respostas a questões sobre grandes processos históricos, dependendo do contexto de diferentes espaços analisados a partir de conjuntos de fontes:

O problema aqui não é tanto opor um alto e um baixo, os grandes e os pequenos, e sim reconhecer que uma realidade social não é a mesma dependendo do nível de análise, ou da escala de observação em que escolhemos nos situar. Fenômenos maciços, que estamos habituados a pensar em termos globais, como o crescimento do Estado, a formação da sociedade industrial, podem ser lidos em termos completamente diferentes se tentarmos apreendê-los por intermédio das estratégias individuais, das trajetórias biográficas individuais ou familiares, dos homens [e mulheres] que foram postos diante deles. Eles não se tornam menos importantes, mas são construídos de maneiras diferentes. (REVEL, 1998, p. 12-13)

São estas experiências individuais e coletivas observadas nas fontes que dão forma e ressignificam os próprios contextos. Portanto, o que defino como limite da "pretensa novidade" da História Global se refere ao fato de que os estudos micro- 
históricos têm implicações globais, quando alternadas as escalas de análise. A escolha do individual não contradiz a do social, porque "permite destacar, ao longo de um destino específico - de um homem, de uma comunidade, de uma obra -, a complexa rede de relações, a multiplicidade dos espaços e dos tempos nos quais se inscreve" (REVEL, 2000, p. 17).

Diferentemente, a História Global baseia muitos de seus estudos em fontes secundárias de historiadores de diversas línguas, apesar de existirem outros tantos baseados em fontes primárias. A partir de um objeto de estudo definido, como pessoas, eventos, fenômenos e mesmo processos, procura compreender sua existência e as conexões possíveis espacializadas em todo o globo ao longo do tempo. Possivelmente, esta ênfase na sincronia seja sua maior contribuição ao debate historiográfico atual. Mas, por causa deste alargamento do tempo e espaço, e de seu exercício de contextualização voltado à maior comparação, a História Global automaticamente produza simplificações e generalizações.

Em texto de 2011, intitulado Is There a Future for Italian Microhistory in the Age of Global History?, a historiadora italiana Francesca Trivellato considerou que não importa o quanto historiadores globais se proponham a desafiar narrativas eurocêntricas e teleológicas anteriores, porque eles, às vezes, também reproduzem generalizações ligadas a essas mesmas narrativas, especialmente quanto desdobram-se em macroescalas (TRIVELLATO, 2011, p. 01). A autora considerou proveitosas à autorreflexão da História Global as ponderações da Micro-História sobre micro e macro-escalas:

Devemos admitir que a micro-história é inadequada para o estudo das mudanças ao longo do tempo. Ela descobre detalhes que são significativos o suficiente para minar os fundamentos das grandes narrativas existentes, mas luta para substituílos por novos. Mais como antropólogos do que como sociólogos, os microhistoriadores desvendam conexões ocultas entre aspectos de um sistema social e cultural que seriam invisíveis para uma macro-análise. (TRIVELLATO, 2011, p. 18) Tradução da autora².

Neste seguimento, em um ensaio de 2015, Carlo Ginzburg ressaltou que a MicroHistória, longe de se opor à História Mundial, pode ser considerada uma ferramenta indispensável dela (GINZBURG, 2015, p. 446), no sentido de que Micro-História e macro-história, isto é, análise detalhada e perspectiva global, longe de serem exclusivas, reforçam-se mutuamente (GINZBURG, 2015, p. 472).

No já aludido texto de 2011, Revel, Stuck e Ferris também trataram do problema metodológico de criar evidências a partir das múltiplas escalas que a perspectiva da História Transnacional oferece: como podemos praticar e espacializar a História Transnacional alternativamente? Como relacionar perspectivas de escopos totalmente diferentes? Os autores afirmaram que não se trata apenas de reduzir a escala ao nível micro de um indivíduo, de uma cidade ou de uma região, a fim de encontrar evidências que possam ser implementadas ou comparadas em análise transnacional. Além disso, deve-se contemplar o benefício explicativo mais amplo proporcionado pelo enfoque sobre a pequena escala, a experimentação dos processos macro dentro instituições específicas (STUCK, FERRIS, KATE \& REVEL, 2011, p. 579) ${ }^{3}$.

\footnotetext{
2 Do original: "We must admit that microhistory is ill-suited to the study of change over time. It digs out details that are significant enough to undermine the foundations of existing grand narratives, but struggles to replace them with new ones. More like anthropologists than sociologists, microhistorians unravel hidden connections between aspects of a social and cultural system that would be invisible to a macro analysis".

3 Giovanni Levi foi além e criticou de maneira contundente as bases do que se convencionou chamar de
} 
Apesar de haver limitado os preceitos que caracterizam a atualidade da História Global, reconheço a pertinência das críticas e propostas de seus estudiosos ao debate historiográfico no que se refere à valorização de conexões transnacionais voltadas ao tempo e ao espaço, e à contrariedade ao eurocentrismo e ao nacionalismo metodológico. A discussão apresentada sobre a relação entre História Global e MicroHistória e o enfoque à dialética entre as escalas não pretende resolver e nem tampouco esgotar o problema da História Global, haja vista a variedade de perspectivas que têm envolvido sua definição enquanto novo campo historiográfico.

A seguir, problematizarei a representatividade de uma fonte específica e localizada para a construção de uma narrativa histórica que aborde temas de experiência global como as políticas estatais sobre colonização, imigração, nacionalidade e cidadania no século XIX. Minha abordagem pouco difere daquela definida pelo historiador italiano Edoardo Grendi como "normal-excepcional", segundo a qual uma fonte que aparentemente seja excepcional pode constituir-se como uma prática comum no cotidiano social ou, que, ao contrário, possa ser, de fato, incomum, e ressignificar seu contexto (BURKE, 1992, p. 158). Além disso, o que pretendo salientar é a ênfase de uma perspectiva transnacional articulada à alternância das escalas de observação.

\section{Imigração e cidadania pelo acesso à terra no século XIX}

No livro A world connecting: 1870-1945, a historiadora estadunidense Emily Rosenberg afirmou que existem diversas maneiras de criarmos padrões abrangentes na história mundial. Apesar de muitas pesquisas desdobrarem-se cronologicamente em torno de grandes eventos ou de áreas geográficas definidas como Europa, África, Ásia, Oriente Médio e América Latina, "romper com uma cronologia comum e uma abordagem "área-por-área" pode ajudar a revelar a dinâmica geral entre alcance e contenção - entre fluxo e tentativas de estabilização - que caracterizou e deu variedade à história do mundo nesta época" (ROSENBERG, 2012, p. 04)4. Faz-se necessário superar as abordagens cronológicas e espaciais tradicionais para contemplar a variedade das experiências históricas ao longo do tempo, criando um novo padrão de temas pautado no multicentrismo e na perspectiva em rede (ROSENBERG, 2012, p. 99).

A partir da segunda metade do século XIX, o mundo tornou-se um lugar ao mesmo tempo mais familiar e estranho à medida que navios rápidos, ferrovias, linhas de telégrafo alcançavam o interior e "apagavam a distância". A troca de pessoas e produtos se acelerou, enquanto o fascínio por viajar e descrever áreas estrangeiras atingiu novos patamares (ROSENBERG, 2012, p. 03). A autora condicionou a diminuição das distâncias geográficas pelo desenvolvimento de tecnologias como navios a vapor, ferrovias e telégrafos, que viabilizaram maior deslocamento e comunicação de pessoas e produtos a áreas até então menos conhecidas do globo, e que aceleraram o processo da interconectividade global.

Para o historiador alemão Jürgen Osterhammel, nenhuma outra época na história além do século XIX houve uma migração de longa distância em uma escala tão maciça (OSTERHAMMEL, 2014, p. 154). Entre 1815 e 1914, pelo menos 82 milhões de

História Global. Cf. LEVI, Giovanni. "Microhistoria e Historia Global”. Historia Crítica, n. 69 (2018): 21-35.

4 Traduzido pela autora do original: "[...] breaking away from a common chronological spine or an area-byarea approach can help reveal the overall dynamic between outreach and containment - between flux and attempts to stabilize - that characterized and gave variability to world history in this era". 
pessoas se deslocaram voluntariamente de um país a outro por intermédio das tecnologias mencionadas por Rosenberg, em fluxos migratórios massivos como aos Estados Unidos, Argentina e Austrália. A migração de dezenas de milhões de europeus à América foi considerada pelo autor de diferentes maneiras, a saber:

Como migração que parcialmente se desenvolveu da migração de dentro da Europa; como migração que fazia parte do povoamento secular da América; como uma invasão hostil das terras dos nativos americanos; na perspectiva da história social, como a criação e a expansão de sociedades imigrantes (diásporas) existentes, sociologicamente, como uma coleção de fenômenos de aculturação; economicamente, como a abertura de novos recursos e o aumento do possível nível global de produtividade; politicamente, como voo de um velho mundo repressivo de uma velha ordem monárquica para o reino da liberdade igualitária; culturalmente, como uma etapa da ocidentalização do mundo a longo prazo. (OSTERHAMMEL, 2014, p. 154) Tradução da autora ${ }^{5}$.

Grande parte deste fluxo migratório europeu constituiu o processo de colonização da América no Oitocentos. Em meados do século, a ideia de atrair imigrantes europeus existiu na maior parte dos países americanos com abundância relativa de terras. Segundo a historiadora argentina María Verónica Secreto, que produziu uma história comparada entre Argentina e Brasil, "as classes dirigentes sulamericanas clamavam por imigrantes europeus, alardeando as vantagens desses trabalhadores em comparação com os escravos. Os braços europeus regenerariam esses países, impulsionariam o desenvolvimento econômico e modernizariam os costumes" (SECRETO, 2012, 2014). Segundo a autora, neste contexto, "grandes extensões de terra no mundo foram incorporadas à produção" de relações capitalistas, pela expansão econômica e a implantação do regime de propriedade privada sobre territórios qualificados como "vazios", "embora 'cheios' de povos originários e de outros usos não capitalistas".

No Brasil, a imigração era defendida como a solução à dependência ao trabalho escravo e ao atraso da modernização da agricultura, atendendo a duas demandas específicas: enquanto mão-de-obra livre às plantações de café do sudeste ao mercado agroexportador sob os regimes de parceria e colonato (em substituição à mão-de-obra africana, cujo tráfico fora proibido pela Lei $n^{\circ} 581$, de 04 de setembro de 1850), e também à atração de colonos na condição de pequenos proprietários às províncias do sul, para o aumento da produção de alimentos ao mercado interno. Subjazia o pressuposto de que estes imigrantes motivariam a "civilidade" e o "progresso" do país por meio do trabalho livre. Em 1867, Tavares Bastos declarou que "a imigração deixou de ser, como o êxodo dos hebreus, o exílio forçado, para se tornar o mais eficaz instrumento de civilização do globo" (TAVARES BASTOS, 1976, p. 51).

De acordo com o historiador brasileiro Paulo Cézar Gonçalves, um componente da política imigrantista era "seu sentido racista", que "valorizava o europeu branco em detrimento dos escravos, libertos e pobres livres. Entre os membros das elites política e intelectual predominavam teorias de "branqueamento", segundo as quais

\footnotetext{
5 "As migration that partly developed out of migration within Europe; as imigration that was part of the centuries-long settlement of America; as a hostile invasion of land belonging to native americans; in the perspective of social history, as the creation of new, and expansion of existing, immigrant (diaspora) societies; sociologically, as a collection of phenomena of acculturation; economically, as the opening up of new resources and the raising of the possible global level of productivity; politically, as flight from a repressive Old World - from a monarchial old order to the realm of equalitarian liberty; culturally, as a stage in the longterm westernization of the world."
} 
pressupunha-se a inferioridade dos indivíduos de cor negra, teoricamente propensos à maior desorganização social e a doenças, e por isso justificava-se a importação de colonos brancos para a miscigenação da classe trabalhadora (GONÇALVES, 2017, s.p.). Neste sentido, a antropóloga Giralda Seyferth reconheceu que o racismo teve papel importante na ideação da sinonímia entre raça e nação; por outro lado, a eugenia do conteúdo racial influenciou as políticas imigratórias como ciência dedicada ao controle das populações (SEYFERTH, 2002, p. 136-137).

O Governo brasileiro consensuou que subvencionaria os serviços de importação e estabelecimento de colonos pobres europeus ao sul do Império a partir da oferta de venda de pequenos lotes de terra. O investimento na formação de colônias de imigrantes cresceu a partir de 1850, ano em que foi promulgada a Lei $n^{\circ} 601$, de 18 de setembro, que regulamentara a colonização estrangeira a ser promovida pelo Governo. Seu projeto inicial foi parcialmente inspirado em debates sobre a colonização nos Estados Unidos e em estudos do economista e administrador colonial britânico Edward G. Wakefield acerca da colonização espontânea na Austrália. Em uma série de ensaios, Wakefield propunha executar a colonização australiana pelo encarecimento artificial do preço das terras, dificultando o acesso imediato dos imigrantes à propriedade particular. Para tornar a colonização sistemática, os imigrantes deveriam tornar-se trabalhadores assalariados e o produto das vendas de terra a prazo deveria ser empregado na importação de novas levas de imigrantes ${ }^{6}$.

Desta forma, a Lei brasileira previa que o rendimento sobre as vendas de terras devolutas e o direito de chancelaria sobre os títulos de posses fosse exclusivamente aplicado à medição de terras e à importação de imigrantes. O Governo ficava autorizado a mandar vir anualmente "certo número de colonos livres para serem empregados em estabelecimentos agrícolas, em trabalhos dirigidos pela administração pública, ou na formação de colônias nos lugares em que estas mais convie[ss]em"7. Conforme aconselhara Wakefield, as autoridades responsáveis deveriam antecipadamente tomar as medidas necessárias para que os colonos achassem emprego "logo que desembarcassem"8, viabilizando que servissem de mão-de-obra e acumulassem o valor da compra do lote a longo prazo. Entretanto, a historiadora brasileira Lígia Osorio Silva esclareceu que o Governo "não estava investindo na criação de um mercado de trabalho livre, regulado pelas leis de mercado, mas propondo um sistema híbrido de retenção da mão-de-obra por formas de coação extra econômica" (SILVA, 1996, p. 104), a exemplo do preço oneroso das terras. $\mathrm{O}$ artigo 14 §2 estabelecia que os preços variariam "de meio real, um real, real e meio, e dois reis por braça quadrada" ${ }^{9}$. Os estrangeiros que

\footnotetext{
${ }^{6}$ Esta tornou-se a explicação clássica sobre a história da Lei de Terras, segundo a qual a Lei consagrou a propriedade privada no país. A compra foi normatizada como a única forma de acesso às terras devolutas, e a posse, proibida. Passou a ser obrigatório que posseiros e sesmeiros em situação irregular requisitassem a legalização e a titulação de suas propriedades, e as registrassem em uma instituição paroquial para que o governo tomasse conhecimento da demanda de medições nos municípios, a fim de discriminar quais eram as terras devolutas aptas à venda. Cf. MARTINS, 1986.

${ }^{7}$ BRASIL, Lei $\mathrm{n}^{\circ}$. 601, de 18 de setembro de 1850, dispõe sobre as terras devolutas do Império, art. $\mathrm{n}^{\circ} 18$. São deste período também o Decreto $n^{\circ} 885$, de 4 de outubro de 1856, que autorizou o Governo a despender até seis mil contos de reis em três anos com a importação de colonos e seu estabelecimento; e o Decreto $n^{\circ} 1.915$, de 28 de março de 1857, que aprovou o contrato entre a Associação Central de Colonização e o Governo Imperial.

8 Ibidem

${ }^{9}$ BRASIL, Lei $n^{\circ}$. 601, Op. cit., art. 14§2. Comparativamente, o preço era mais barato nos Estados Unidos, principalmente a partir da promulgação da lei dos preços graduados, de 14 de agosto de 1854, que previa que as terras não compradas em hasta pública por dez anos poderiam ser vendidas a um dólar o acre, no fim de quinze anos, a 75 cents, no fim de vinte anos, a 50 cents, no fim de trinta anos a 12 e $1 / 2$ cents, o que representava a metade dos menores preços estipulados pelo Governo brasileiro. Em 1862, o Governo
} 
comprassem terras e se estabelecessem no Brasil, após dois anos de residência, se quisessem, poderiam requerer a naturalização como cidadãos brasileiros ${ }^{10}$.

Esta política de importação de imigrantes pobres europeus participou do processo de consolidação do Estado Imperial brasileiro e motivou a revisão dos dispositivos legais sobre direitos de naturalização e cidadania. A Constituição de 1824 outorgara que eram cidadãos brasileiros "os estrangeiros naturalizados"; "os que no Brasil tive[ss]em nascido ingênuos ou libertos ainda que o pai [fosse] estrangeiro e que este não resid[isse] por serviço de sua Nação"; "todos os nascidos em Portugal e suas possessões" que aderiram a Independência, etc ${ }^{11}$. Esta definição sobre quem era cidadão excluía estrangeiros e privilegiava os homens brancos, apesar de que, mesmo entre estes, os direitos civis e políticos eram distintos, dependendo de fatores como renda e gênero. Por exemplo, somente homens com renda anual superior a 100 mil reis eram considerados ativos ao voto em eleições primárias (DAL LRI, 2010, p. 18). O status de cidadão ativo não era, portanto, vinculado de maneira irrestrita aos homens brancos nacionais, mas àqueles também tornados nacionais e proprietários.

A Lei de 23 de outubro de 1832 havia regulamentado o tempo de quatro anos de residência no Brasil para a naturalização de estrangeiros, desde que fossem maiores de 21 anos e possuíssem bens de raiz no país, que tivessem parte em fundos de estabelecimento industrial, ou que simplesmente vivessem "honestamente do seu trabalho"12. A naturalização de colonos estrangeiros regulamentada na Lei de Terras foi complementada pelo Decreto $\mathrm{n}^{\circ} 808$, de 23 de junho de 1855. Após dois anos de residência, os estrangeiros interessados em naturalizar-se deveriam "assinar perante a Câmara ou juizado de Paz um termo de ser essa sua vontade", e o pedido seria analisado pelos presidentes de província. $\mathrm{O}$ art. $\mathrm{n}^{\circ} 03$ especificava que o Governo concederia títulos de naturalização "aos colonos que julga[sse] dignos" antes mesmo do prazo de dois anos. Esta disposição e a própria diminuição de quatro para dois anos do período de residência à naturalização exemplifica a intenção do Governo de facilitar aos europeus a possibilidade de tornarem-se cidadãos brasileiros.

O Decreto $\mathrm{n}^{\circ} 3.784$, de 19 de janeiro de 1867, sobre as colônias do Estado, simplificou ainda mais este processo, pois previa aos imigrantes que comprassem a prazo o pagamento em cinco prestações durante o período de sete anos, e que fosse descontado $6 \%$ sobre as parcelas pagas antes do prazo ${ }^{13}$. Além disso, "no dia em que o colono entra[sse] na posse do seu lote, Ihe entregara[ria] o Diretor, como auxílio gratuito para o primeiro estabelecimento a quantia de $20 \$ 000$ e ao que fo[sse] chefe de família um donativo igual por pessoa maior de 10 anos e menor de 50"14. Os colonos teriam direito a receber também "as sementes mais necessárias para as primeiras plantações destinadas ao seu sustento, e bem assim os instrumentos agrários de que

estadunidense promulgou o Homestead Act, que permitia a qualquer cidadão nacional ou estrangeiro, maior de 21 anos, tornar-se proprietário de 160 acres de terra pelo valor de 10 dólares para despesa de cadastro, desde que cultivasse o solo por cinco anos. SILVA, Lígia Osório, Op. cit., p. 148.

10 BRASIL, Lei $n^{\circ} .601$, Op. cit., art. nº 17.

11 Cf. Constituição política do Império do Brazil (25 de março de 1824), art. n 06. Disponível em: http://www.planalto.gov.br/ccivil_03/Constituicao/Constituicao24.htm.

12 Lei de 23 de outubro de 1832 , sobre a naturalização dos estrangeiros, art. 01. Disponível em: http://www2.camara.leg.br/legin/fed/lei_sn/1824-1899/lei-37324-23-outubro-1832-563838-

publicacaooriginal-87885-pl.html

${ }_{13}$ Decreto $n^{\circ} 3.784$, de 19 de janeiro de 1867, aprova o regulamento para as colônias do Estado, art nº6. Disponível:http://www2.camara.leg.br/legin/fed/decret/1824-1899/decreto-3784-19-janeiro-1867-553854publicacaooriginal-72121-pe.html.

14 Decreto $\mathrm{n}^{\circ} 3.784$, de 19 de janeiro de 1867, aprova o regulamento para as colônias do Estado, art. $\mathrm{n}^{\circ}$ 30 . 
precisa[ss]em", sendo seu custo adicionado ao da "derrubada, casa provisória e de qualquer adiantamento", somado ao preço da terra a ser pago conjuntamente ${ }^{15}$.

No Arquivo Público do Estado de Santa Catarina, na pasta intitulada Requerimentos de diversos para Diretoria de Terras e Colonização e Presidente da província, consta um abaixo-assinado realizado em 30 de setembro de 1886 por quinhentos e trinta e cinco homens residentes no município catarinense de Tubarão. Recebido pelo Diretor Especial de Terras e Colonização, em Desterro, o requerimento seria remetido ao Imperador do Brasil D. Pedro II, cujo conteúdo é o seguinte:

Senhor,

Os abaixo assinados, cidadãos brasileiros, lavradores, pobres, sem terras próprias para trabalhar, vivendo sob o onerosíssimo regime do arrendamento de terras que Ihes agrava a mísera situação, considerando que, além de ser justíssima a pretensão dos suplicantes abaixo expressa, acha-se ela explicitamente formulada no luminoso programa do atual Ministério; considerando que não podem, não devem, ser falazes as promessas que do alto da tribuna parlamentar foram feitas ao país pelo Excelentíssimo Senhor Presidente do Conselho; considerando que os favores feitos aos estrangeiros imigrantes, de concessão de lotes de terras medidas a prazo de sete anos para pagamento, trazem, como consequência, a depressão moral dos nacionais e suas funestas consequências, considerando que não deve ser o próprio Governo do país o primeiro a atirar os nacionais aos horrores da miséria, lançando sobre eles o infame estigma de indolentes, de imprestáveis, quando o oposto deve ser e é o nobre papel de prospector nato que lhe cabe; considerando que na província do Paraná, os nacionais gozam dos mesmos favores acima expostos que os imigrantes graças a ação benéfica que ali exerceu 0 Excelentíssimo Senhor Doutor Taunay; vem os suplicantes humildemente impetrar a Vossa Majestade Imperial a graça de mandar que aos nacionais desta província sejam distribuídos lotes de terras nas mesmas condições que aos imigrantes recémchegados. Por todas estas considerações, os suplicantes ousam esperar de Vossa Majestade Imperial favorável deferimento. Tubarão, 30 de setembro de $1886^{16}$.

Por meio da Repartição Especial, os 535 lavradores brasileiros pobres e semterra reclamaram ao Imperador os benefícios de acesso à propriedade concedidos pelo Governo aos estrangeiros imigrantes constantes no Decreto de 1867, e valeram-se deste direito criado especialmente a esses estrangeiros para basear a justiça de sua pretensão, de que também lhes fossem distribuídos lotes de terras com a condição de pagamento a prazo de sete anos.

O abaixo-assinado exemplifica como a imigração e a colonização estrangeira criaram relações de alteridade entre brasileiros e imigrantes que extrapolam a cidadania nacional e a redefinem com base em parâmetros políticos e nos direitos criados aos colonos europeus, a partir da facilitação nos processos de naturalização e de aquisição fundiária. Veja que ao se afirmaram cidadãos brasileiros, os abaixo assinados censuraram o fato de que apenas estrangeiros recém-chegados, isto é, não-cidadãos do Império, recebiam "favores" de acesso à propriedade, ao passo que eles, cidadãos nacionais, nem sequer dispunham de terras próprias. Isto posto, consideremos que a própria cidadania e a identidade nacional brasileira têm origem em um processo transnacional.

O Recenseamento de 1872 indicou que o município de Tubarão, onde o abaixo-

15 Decreto $\mathrm{n}^{\circ} 3.784$, de 19 de janeiro de 1867, aprova o regulamento para as colônias do Estado,, art. $\mathrm{n}^{\circ}$ 31.

16 BRASIL, Arquivo Público do Estado de Santa Catarina. Requerimentos de diversos para Diretoria de Terras e Colonização e Presidente de província 1885/1888, fls. 10-19 v. 
assinado fora realizado quatorze anos depois, possuía 7.608 homens e mulheres livres e escravos(as) ${ }^{17}$. Deste total, havia 3.540 "homens livres" (cerca de $46,5 \%$ da população), dos quais 3.152 eram "brancos"; 204 "pardos"; 124 "caboclos" e sessenta "pretos". Do total de homens livres, dezesseis eram "estrangeiros" (dois alemães, dois espanhóis e quatro portugueses) e 3.524 eram "brasileiros", representando 99,5\%. Dentre os homens livres classificados em relação às profissões, existiam 2.066 "lavradores", 274 em "serviço doméstico", 114 "criados e jornaleiros", além de profissões liberais como advogados, comerciantes, etc., sendo a agricultura, portanto, a atividade laboral de mais de $58 \%$ dos homens livres ${ }^{18}$. Apesar de no Recenseamento não haver informações sobre a renda para refletirmos a existência dos autodenominados "pobres", se considerarmos que mais de $99 \%$ da população livre de Tubarão era nacional, que mais de $46 \%$ eram homens livres, e que mais de $58 \%$ eram lavradores, em 1886 , os 535 abaixo assinados representavam parte considerável dos moradores do município em 1871.

Foi exatamente a partir de meados de 1870 que o número de imigrantes estrangeiros começou a aumentar em Tubarão, e na década seguinte, quando o abaixoassinado foi lavrado, a região recebeu fluxos maiores especialmente de italianos para colonização e a construção da estrada de ferro Donna Thereza Christina. Esta ferrovia foi construída após a concessão de terras devolutas e das companhias da linha férrea e de mineração pelo Governo ao Visconde de Barbacena e a investidores ingleses, com a criação da The Donna Thereza Christina Railway Company e da Tubarão Coal Mining Company Limited, ambas companhias de Londres, responsáveis pela exploração e transporte de carvão mineral das margens do rio Tubarão aos portos nacionais de Imbituba e Laguna, ao Rio de Janeiro e à Europa ${ }^{19}$. Por este motivo o baixo número de estrangeiros no Recenseamento de 1872 deve ser desconsiderado para a década seguinte.

Em 1884, foi fundada em Tubarão uma Sociedade de Imigração, responsável pela promoção da imigração espontânea. O presidente Francisco Luiz da Gama Roza declarou que "cessaria completamente a imigração para a província, se não fo[ssem] as beneméritas associações de Hamburgo e do Grão Pará, que a promovessem e a encaminhassem às fertilíssimas terras de Tubarão" ${ }^{20}$. No relatório de 1883, Gama Roza declarou que

A ex-colônia Azambuja, fundada em 13 de abril de 1877, pertence ao município de Tubarão, ocupando uma superfície calculada e 248 milhões de metros quadrados, dos quais se acham cultivados 15 milhões. Essa ex-colônia, sendo a última fundada na província, possuindo um terreno fertilíssimo, tem se desenvolvido consideravelmente, graças aos esforços dos colonos que ali atualmente habitam. Grande quantidade de colonos espontâneos tem a ela afluído, principalmente ao distrito de Urussanga, onde cerca de 80 famílias de imigrantes têm requerido compra de terras para se estabelecerem ${ }^{21}$.

\footnotetext{
17 RECENSEAMENTO DO BRASIL EM 1872, SANTA CATARINA. "Quadro Geral da população da paróquia de Nossa Senhora da Piedade do Tubarão, p. 109-111.

18 Tubarão era o quinto distrito do município de Laguna, denominado Poço Grande do rio Tubarão, emancipado em 27 de maio de 1870.

${ }^{19}$ Cf. Decreto $n^{\circ}$ 8.856, de 19 de janeiro de 1883, autoriza a The Tubarão Coal Mining Company, limited para funcionar no Império. Disponível em: http://www2.camara.leg.br/legin/fed/decret/1824-1899/decreto8856-19-janeiro-1883-544212-publicacaooriginal-55194-pe.html.

${ }^{20}$ BRASIL, Fala com que o Ex. Sr. Dr. Francisco da Gama Roza abriu a primeira sessão da vigésima quinta legislatura da Assembleia Legislativa da província de Santa Catarina em 05 de fevereiro de 1884, p. 07.

21 BRASIL, Relatório com que o Ex. Sr. Dr. Francisco Luiz da Gama Roza passou a administração da
} 
Do ponto de vista dos lavradores nacionais, é-nos difícil compreender o significado atribuído às transformações sociais e do território em Tubarão com a chegada e os "esforços" dos colonos estrangeiros. De todo modo, seu abaixo-assinado demonstra que não estiveram passivos a este processo e que concentraram esforços a satisfizerem suas demandas nesta política junto ao Governo.

Indiretamente, o abaixo-assinado é uma resposta local destes camponeses nacionais sem-terra à política de colonização estrangeira implementada pelo Governo, e expressa uma resistência a este modelo de modernização e à legislação vigente que favorecia o acesso à propriedade privada exclusivamente a colonos estrangeiros. Ao recorrerem a esse dispositivo legal, queixando-se da dificuldade sofrida por não usufruírem dos mesmos direitos, os abaixo assinados esquivaram-se da marginalização a que estavam reputados, o que tudo indica a agência camponesa frente às políticas do Governo.

Segundo eles, a desigualdade de favores concedidos a estrangeiros e nacionais seria a causa de sua "depressão moral", do estigma de indolentes e principalmente de sua pobreza. Isto porque, ao não possuírem a propriedade das terras que trabalhavam, estavam sujeitos ao regime de arrendamento, no qual, por meio de um contrato formal ou informal, proprietários ou grandes senhores de terras cediam temporariamente 0 usufruto e a ocupação de terrenos a lavradores nacionais, que produziam sua subsistência em troca do pagamento de uma renda ou aluguel (MOTTA, 2005, p. 4043), o que era "onerossíssimo" e "agravava a mísera situação" dos abaixo assinados.

O regime de arrendamento fundiário foi regulamentado pelas Ordenações Filipinas como um contrato de exploração com duração inferior a dez anos, em que o senhorio transferia o uso do imóvel ao arrendatário mediante prestação anual de uma renda fixa ${ }^{22}$. Ao contrário da enfiteuse, o arrendamento não gerava o desmembramento dos direitos de propriedade nem a transferência do domínio para o rendeiro, conferindo apenas o direito de usufruto. As Ordenações previam ainda uma forma específica de arrendamento denominada "parceria", que se distinguia pela renda corresponder a uma parte da produção do arrendatário e pelo contrato finalizar no caso de morte de uma das partes $^{23}$.

No Brasil Imperial, ambas as modalidades de arrendamento coexistiram e geraram um subproduto denominado "agregado", em referência à relação pessoal na qual grandes proprietários permitiam que nacionais pobres ocupassem "de favor" pequenos lotes de terras nas bordas de suas propriedades mediante a concessão de dias de trabalho do agregado e de sua família ou da entrega de parte da lavoura como pagamento pelo usufruto da terra.

Para a historiadora Marina Monteiro Machado, "a relação existente entre o proprietário das terras e o agregado caracteriza-se como uma relação não-capitalista de produção, pois não implicava pagamento de salário, ainda que estivesse inserida dentro de um contexto capitalista" (MOTTA, 2005, p. 20). Havia casos em que a relação se estendia a lealdades e compadrios, garantindo maior amparo político-social do proprietário sobre o agregado. Contudo, esta relação era desigual. A falta de títulos legais que assegurassem o direito de posse sobre os terrenos cultivados gerava insegurança ao agregado, pois o proprietário poderia lhe deixar de prestar o "favor" do

província o Ex. Dr. Teodoreto Carlos de Faria Souto em 29 de agosto de 1883. Desterro: Tipografia do Caixeiro, 1883, p. 21.

22 Ordenações Filipinas, Livro 4, Título 45, §2.

23 Ordenações Filipinas, Livro 4, Título 45, §3. 
usufruto quando quisesse, inclusive com o uso de força.

Os abaixo assinados de Tubarão, mesmo sem a propriedade plena sobre as terras que trabalhavam, reconheceram-se como lavradores que desempenhavam 0 "nobre papel de prospector nato". O sentido da palavra prospector como a pessoa que explora terrenos em busca de minérios é totalmente cabível ao contexto de Tubarão durante a segunda metade do século XIX, não apenas pelo fato da existência do carvão mineral na região, mas principalmente porque esta exploração era realizada em terras devolutas, onde a posse com moradia habitual e cultura efetiva era possível sem a intervenção de proprietários (o que não excluía a possibilidade de conflito com outros posseiros). Em 1874, a Comissão do Registro Geral e Estatística das Terras Públicas e Possuídas de Santa Catarina relatou que a maior parte da região sul era formada por terras devolutas:

Poder-se-á calcular a superfície em cerca de quatrocentas léguas quadradas, na sua máxima parte devolutas, pois que, segundo as datas e informações existentes, apenas estão habitadas as margens do Tubarão, principalmente em toda a extensão navegável por iates, até o lugar denominado de N. S. Piedade; bem como alguns pontos dos rios Capivary e Braço do Norte, para onde se tem dirigido bastantes colonos $^{24}$.

O direito de preferência dos posseiros para a legitimação e a compra de terras devolutas era o que diferia a agricultura brasileira da teoria da renda fundiária de Karl Marx. O desenvolvimento do capitalismo no Brasil ocorreu em um contexto que, como observamos em Tubarão, contava com a existência de terras devolutas, com uma fronteira agrícola e de ocupação ainda aberta, em que o monopólio da terra não era total, apesar de haver sido revertido ao Estado pela Lei de Terras.

Para María Verónica Secreto, contudo, esta "disponibilidade de terras agravou a situação dos despossuídos, sobre os quais se estendeu um severo dispositivo de controle social" (SECRETO, 2012, p. 120). A autora explicou que após a abolição da escravidão na Argentina, a regulamentação dos Códigos Rurais sobre mão-de-obra restringiu a livre circulação de pessoas no campo e declarava como "vadios" todos os que não possuíssem residência fixa e ocupação declarada:

A legislação e as práticas policiais pretendiam terminar com os prejuízos causados pelos "vadios" à propriedade e obrigá-los a concorrer ao mercado. Para isso, implementaram-se critérios coercitivos com uma legislação que dava garantia à propriedade rural e propunha a eliminação dos circuitos marginais de subsistência. (SECRETO, 2012, p. 197)

No Brasil, apesar de não haver existido códigos rurais, o Governo, por meio de recrutamento compulsório, igualmente restringiu a mobilidade dos pobres livres e estrategicamente os redistribuiu no Império conforme suas demandas (BEATTIE, 2009, p. 27). A Lei de Terras indiretamente atendeu a este objetivo, quando criminalizou a posse de terras devolutas em 1850, obstando seu acesso às populações pobres.

Se analisado no contexto abolicionista da segunda metade do século XIX, com a promulgação das leis $n^{\circ} 2.040$, de 28 de setembro de 1871 (do Ventre Livre), $n^{\circ} 3.270$, de 1885 (dos Sexagenários) e $n^{\circ} 3.353$, de treze de maio de 1888 (da Abolição), o favorecimento do acesso à propriedade a colonos estrangeiros ao invés de nacionais

\footnotetext{
${ }^{24}$ APESC, Descrição topográfica do mapa da província de Santa Catarina organizada na Comissão do registro geral e estatística das terras públicas e possuídas sob a presidência do Conselheiro Augusto Nascente de Azambuja. Rio de Janeiro: Impr. Impériale de S.A. Sisson, 1874.
} 
(estes últimos, incluindo ex-escravos, libertos) pode ser interpretado como uma estratégia do Governo para ampliar a reserva de mão-de-obra barata livre que substituísse a escrava, ao mesmo tempo que promovia a modernização e a "moralidade dos costumes" à la europeia 25 .

A despeito de constituírem a maioria da população livre, responsável pela progressão da produção de alimentos de primeira necessidade, os brasileiros pobres foram marginalizados como cidadãos de segunda categoria e qualificados como indolentes, mantenedores do atraso da indústria agrícola. Em 1870, por exemplo, foi publicado na capital da província que

O nosso lavrador trabalha enquanto possui nas suas terras matos a derrubar e queimar. Quando esses matos acabam, quando a terra cansa e não produz mais, segundo a crença rural nossa patrícia, o lavrador muda de pouso ou de profissão. O lavrador brasileiro, cujas terras são desmatadas ou só possuem capoeiras, é um artista arruinado, um negociante falido, uma pessoa prestes a morrer ou a despedirse. Depois faltam lenhas, vem o célebre cansaço, e ei-lo em fuga ou de braços cruzados o triste e pobre lavrador! Da sua ruína provém a nossa, a da província, a do Império e seu Governo ${ }^{26}$.

Esta desqualificação esteve presente em grande parte da literatura do século XIX e mesmo do XX. A socióloga Maria Sylvia de Carvalho Franco explicou os lavradores nacionais como "uma ralé que cresceu e vagou ao longo de quatro séculos: homens a rigor dispensáveis, desvinculados dos processos essenciais à sociedade". Para a autora, o sistema escravista teria criado as condições para o desenvolvimento deste contingente populacional "sem razão de ser", por estar desvinculado da produção mercantil (FRANCO, 1997, s.p.).

Em contrapartida, estudos como os do sociólogo José de Souza Martins e de Peter Eisenberg demonstraram que o trabalhador nacional "participava de diversas maneiras da agricultura de exportação por muito tempo antes da abolição" (EISENBERG, 1989, p. 229). Segundo Eisenberg, as referências ao trabalho livre no setor de exportação eram frequentes, "era comum usar o livre nacional, chamado 'camarada', para tarefas perigosas, como o desbravamento da mata" ou em serviços de baixa rentabilidade nas fazendas, como na provisão de gêneros alimentícios, cultivando a terra com milho feijão, mandioca, etc. (EISENBERG, 1989, p. 228). De acordo com Martins, à medida que a expansão da fronteira agrícola avançou ao interior paulista, os camponeses nacionais foram expulsos de suas terras por grandes fazendeiros que os agregavam ao trabalho das fazendas. Trabalhavam no desmatamento dos terrenos às plantações de café que posteriormente seriam encarregadas aos imigrantes, "no habia lugar para ellos dentro de la gran hacienda de café, no obstante, la expansión de los cafetales los incorporó como plantadores" (MARTINS, 1985, p. 234). É possível que o caso da província paulista seja sintomático de um padrão praticado em todo país. $\mathrm{A}$ desterritorialização e a desqualificação dos camponeses nacionais fizeram parte de um longo processo político operado pelas classes dominantes, que promoveram a exploração sistemática e abusiva de sua força de trabalho.

\footnotetext{
${ }^{25}$ Neste sentido, o historiador Peter Eisenberg constatou que na véspera da abolição, o senador paulista Joaquim Floriano Godoy afirmou que "o braço nacional é tão numeroso e hábil para o trabalho que pode, por estirado tempo, encher os claros abertos pelas libertações”. EISENBERG, Peter. Homens esquecidos: escravos e trabalhadores livres no Brasil. Séculos XVIII e XIX. Campinas: Editora da Unicamp, 1989, p. 230.

26 Jornal o Despertador. Desterro, Santa Catarina. Ano VIII, N ${ }^{\circ} 791,20$ de maio de 1870. Acervo da Biblioteca Nacional Digital. Hemeroteca digital, seção periódicos, s. endereço eletrônico.
} 


\section{O abaixo-assinado de 1886: do local ao global}

A princípio, o abaixo-assinado dos camponeses nacionais de Tubarão não parece viabilizar uma abordagem heurística transnacional ou global, porque não apresenta indícios de conexões dos requerentes que se estendam para além das fronteiras do território brasileiro. Entretanto, explorá-lo como fonte histórica à luz do debate sobre a variação das escalas de análise e das histórias Transnacional e Global tem o potencial de redefinir as questões e, consequentemente, os significados de sua representação sobre temas e fenômenos de experiência mundial ou sub-mundial, como agência camponesa, cidadania, políticas imigratórias e de colonização, capitalismo, regime de propriedade privada, etc.

Apesar de a História Global criticar o uso do conceito de Estado-Nação, por restringir a análise histórica a um único país, é também importante compreendê-lo enquanto categoria analítica que dimensiona a fronteira geográfica em que os países independentes se configuraram ao longo do século XIX, com Constituições e políticas próprias. O historiador brasileiro José Murilo de Carvalho explicou que, apesar de a cidadania ter se desenvolvido no contexto da Revolução Francesa de 1789, sofreu variações em diferentes espaços ao longo do tempo, dos direitos civis aos políticos, de modo que "quando falamos de um cidadão inglês, ou norte americano, e de um cidadão brasileiro, não estamos falando da mesma coisa" (CARVALHO, 1999, p. 12). O fato de que "a construção da cidadania tem a ver com a relação das pessoas com o Estado e com a nação", não impede que as influências e conexões das lutas por direitos geralmente sejam transnacionais. Neste aspecto, a própria Lei de Terras é exemplar, pois sua elaboração resultou da interação e circulação transcontinental de ideias sobre a melhor forma de se promover a colonização no século XIX. Como vimos, foi baseada em estudos sobre a colonização australiana e estadunidense, apesar de, obviamente, ter sido aplicada somente no território brasileiro. O que destaco é que foi no contexto desta e das demais leis referidas ao longo do texto que os abaixo assinados de Tubarão procuraram garantir seu acesso à propriedade.

No sentido da crítica da História Global às abordagens espaciais tradicionais, a contextualização múltipla do abaixo-assinado, condicionada pela variação da objetiva, nos permite analisar uma das incontáveis formas pelas quais a colonização europeia foi experienciada em Tubarão no fim do século XIX. Este exercício é importante porque contempla um território definido na época como "sertão", hinterland, periférico do ponto de vista eurocêntrico, e porque destaca a experiência dos trabalhadores livres pobres na utilização estratégica das leis. Em outras palavras: este exercício é importante por contemplar agentes marginalizados de regiões marginalizadas.

A partir das ferramentas conectivas e comparativas da História Transnacional, é possível produzir uma narrativa histórica em que Tubarão e seus munícipes são "desparoquializados" e relacionados ao processo da interconectividade global dita por Rosenberg sobre o século XIX.

Além da imigração estrangeira, em que estavam implicadas a mobilidade e o reagrupamento de pessoas de diferentes territórios e nações na região, havia a autorização do Governo para o investimento de capital inglês com a construção da estrada de ferro - o maior vulto do progresso à época - e a exploração de carvão mineral pelas empresas londrinas The Donna Thereza Christina Railway Co. e The Tubarão Brazilian Railway Coal Mining Co. Limited. O carvão mineral era a matéria-prima propulsora do vapor em locomotivas e navios, portanto imprescindível à expansão dos 
transportes. O presidente provincial Francisco José da Rocha relatou em 1886 que a Grã-Bretanha e a Alemanha eram os países que mais comercializavam com Santa Catarina, e que a base da importação inglesa era o carvão mineral, "gênero reputado de primeira necessidade, de geral cobiça, de universal apreço, que tanto realce tem dado à fortuna pública em todos os países que o exploram"27.

Sem desconsiderarmos a chave-explicativa do neocolonialismo britânico sobre a América Latina, podemos experimentar a análise das transformações da produção em Tubarão no fim do século XIX apoiados na noção de multicentrismo e da perspectiva em rede. A título de exemplo, o historiador Walter Piazza ressaltou que já a Guerra do Paraguai "mostrara ao Brasil a necessidade de produzir combustíveis, como o carvão de pedra para o desenvolvimento da navegação a vapor, para ativamento das estradas de ferro que se construíam no país" (PIAZZA, 1994, p. 170). Ou seja, existem inúmeros elementos de experiências regionais que também ajudam a explicar a construção da linha férrea e da exploração mineral no sul da província catarinense. Para além dos fatores de expulsão do contingente migrante europeu, a importação de mão-de-obra voltada de maneira específica à construção da ferrovia redefine Tubarão como município particularmente atrativo a imigrantes e a investimentos agenciados pelo Governo e empresas particulares.

À guisa de conclusão, a análise do abaixo-assinado indica que em Tubarão havia elementos que convergem e divergem da representação formulada pela cronologia eurocêntrica do século XIX como o século de ascensão da modernidade e da industrialização. Há de se problematizar, por exemplo, o aparente paradoxo entre o desenvolvimento das relações capitalistas na América Latina - com a instituição do regime de propriedade privada e a importação de imigrantes "livres e assalariados" - e a manutenção de relações de trabalho paternalistas e personalistas, assim como de práticas tradicionais de acesso e usufruto da terra, como a posse e o arrendamento "de favor". Todos estes conceitos devem ser refletidos a partir do deslocamento da bússola, a exemplo de Tubarão, pois, de acordo com Revel, "somente esta multiplicidade desordenada e em parte contraditória nos permite dar conta da complexidade das transformações do mundo social" (REVEL, 2010, p. 443).

Este exercício de reinterpretação do caso pelos preceitos da História Global não explorou todas as possibilidades. De forma exploratória, pode-se considerar comparar legislações de outros países, para além da América Latina, apontando semelhanças e diferenças nos diferentes processos de construção jurídica acerca de nacionalidade e o acesso à propriedade e à cidadania, no século XIX. Ademais, pode-se considerar também a investigação da incidência de experiências semelhantes àquela observada em Tubarão, de resistência da população nacional trabalhadora, em outros territórios do país, para além dele e do continente americano. Minha intenção foi proporcionar uma amostragem qualitativa do possível exercício relacional entre História Global e a variação de escalas proposta pela Micro-História.

\footnotetext{
${ }^{27}$ Relatório apresentado à Assembleia Legislativa da Província de Santa Catarina na primeira sessão de sua $26^{a}$ legislatura pelo presidente Dr. Francisco José da Rocha, em 21 de julho de 1886. Desterro, Tipografia do Conservador, 1886, p. 163 e 176.
} 


\section{Referências}

ADELMAN, Jeremy. "What is global history now?". In: Aeon. 02 de março de 2017. Acessado em jan. 2019. Disponível https://aeon.co/essays/is-global-history-stillpossible-or-has-it-had-its-moment.

BRASIL, Arquivo Público do Estado de Santa Catarina. Requerimentos de diversos para Diretoria de Terras e Colonização e Presidente de província 1885/1888, fls. 10-19 v.

BRASIL, Arquivo Público do Estado de Santa Catarina, Descrição topográfica do mapa da província de Santa Catarina organizada na Comissão do registro geral e estatística das terras públicas e possuídas sob a presidência do Conselheiro Augusto Nascente de Azambuja. Rio de Janeiro: Impr. Impériale de S.A. Sisson, 1874.

BRASIL, Fala com que o Ex. Sr. Dr. Francisco da Gama Rosa abriu a primeira sessão da vigésima quinta legislatura da Assembleia Legislativa da província de Santa Catarina em 05 de fev. de 1884.

BRASIL, Relatório apresentado à Assembleia Legislativa da Província de Santa Catarina na primeira sessão de sua $26^{a}$ legislatura pelo presidente Dr. Francisco José da Rocha, em 21 de julho de 1886. Desterro, Tipografia do Conservador, 1886.

BRASIL, Mapa da Comissão do Registro Geral e Estatística das Terras Públicas e Possuídas. Mapa topográfico de parte da Província de Santa Catarina: compreendendo as comarcas do litoral, colônias e terras públicas adjacentes às mesmas colônias. 1872 . Acervo da Biblioteca Digital Luso Brasileira.

BEATTIE, Peter. Tributo de sangue: exército, honra, raça e nação no Brasil, 1864-1945. Tradução de Fábio Duarte Joly. São Paulo : EDUSP, 2009.

BURKE, Peter (org.). A escrita da história: novas perspectivas. Tradução de Magda Lopes. São Paulo: Ed. da UNESP, 1992.

CARVALHO, José Murilo de. Cidadania no Brasil: o longo caminho. Rio de Janeiro: Civilização Brasileira, 1999.

CONRAD, Sebastian. What is global history? Princeton: Princeton University Press, 2016.

CROSSLEY, Pamela Kyle. O que é história global? Tradução Vera Joscelyne. Rio de Janeiro: Editora Vozes, 2015.

DAL RI, Luciene. "A construção da cidadania no Brasil: entre Império e Primeira República". In: Espaço Jurídico. Joaçaba, v. 11, n. 1, p. 7-36, jan./jun. 2010, p. 07-36.

EISENBERG, Peter. Homens esquecidos: escravos e trabalhadores livres no Brasil. Séculos XVIII e XIX. Campinas: Editora da Unicamp, 1989.

FRANCO, Maria Sylvia de Carvalho. Homens livres na ordem escravocrata. $4^{a}$ Edição. São Paulo: Unesp, 1997.

FICKER, Sandra Kuntz. "Mundial, trasnacional, global: Un ejercicio de clarificación conceptual de los estudios globales". In: Nuevo Mundo Mundos Nuevos [En ligne], Débats, mis en ligne le 27 mars 2014. 
GINZBURG, Carlo. "Microhistory and World History." In: The Cambridge World History, edited by Jerry H. Bentley, Sanjay Subrahmanyam, and Merry E. Wiesner-Hanks. Cambridge: Cambridge University Press, 2015, pp. 446-73.

GONÇALVES, Paulo Cezar. "Escravos e imigrantes são o que importam: fornecimento e controle da mão de obra para a economia agroexportadora Oitocentista". In: Almanack Guarulhos. №.17, Sept./Dec. 2017, s.p.

Giovanni. A herança imaterial: trajetória no Piemonte no século XVII. Tradução de Cynthia Marques de Oliveira. Rio de Janeiro: Civilização Brasileira, 2000.

Levi, Giovanni. "Microhistoria e Historia Global". Historia Crítica, n. 69 (2018): 21-35.

MACHADO, Paulo Pinheiro. A política de colonização do Império. Porto Alegre: Editora Universidade UFRGS, 1999.

MARTINS, José de Souza. O cativeiro da terra. $2^{\text {a }}$ Ed. São Paulo: Hucitec, 1986.

MARTINS, José de Souza "Del esclavo al asalariado en las haciendas de café, 18801914. La Génesis del trabajador volante”. In: SANCHEZ ALBORNOZ, Nicolás. Población y mano de obra en América Latina. Madrid: Alianza, 1985.

MOTTA, Márcia (org.). Dicionário da terra. Rio de Janeiro: Civilização Brasileira, 2005.

OSTERHAMMEL, Jürgen. The transformation of the world: a Global History of the nineteenth century. Translated by Patrick Camiller. Princeton: Princeton University Press, 2014.

PIAZZA, Walter Fernando. A colonização de Santa Catarina. $3^{a}$ Edição. Florianópolis: Editora Lunardelli, 1994.

REVEL, Jacques (org.). Jogos de escalas: a experiência da microanálise. Tradução Dora Rocha. Rio de Janeiro: Editora FGV, 1998.

REVEL, Jacques. "Micro-história, macro-história: o que as variações de escala ajudam a pensar em um mundo globalizado". In: Revista Brasileira de Educação. Vol. 15, n 45. Rio de Janeiro, dez. 2010, pp. 434-444.

ROSENBERG, Emily S. (edited by). A world connecting 1870-1945. Cambridge and London: The Belknap Press of Harvard University Press, 2012.

SECRETO, María Verónica. Fronteiras em movimento: História Comparada - Argentina e Brasil no século XIX. Niterói: Editora da UFF, 2012.

SEYFERTH, Giralda. "Imigrantes, estrangeiros: a trajetória de uma categoria incômoda no campo político". In: Sítio da Associação Brasileira de Antropologia. In: REUNIÃO BRASILEIRA DE ANTROPOLOGIA, 26, 2008, Salvador. Anais... Salvador, UFBA, 2008. p. 1-20 p. 9.

SEYFERTH, Giralda. "Colonização, imigração e a questão racial no Brasil". REVISTA USP, São Paulo, n.53, p. 117-149, março/maio 2002.

SILVA, Lígia Osório. Terras devolutas e Latifúndio: efeitos da Lei de Terras de 1850. Campinas: Ed. Unicamp, 1996. 
STUCK, Bernhard, FERRIS, Kate \& REVEL, Jacques (2011) "Introduction: Space and Scale in Transnational History”. The International History Review, 33:4, 573-584.

TAVARES BASTOS, Aureliano Candido. Os males do presente e as esperanças do futuro. $2^{a}$ edição. São Paulo: Cia Ed. Nacional, Brasília: INL, 1976.

TRIVELLATO, Francesca. "Is There a Future for Italian Microhistory in the Age of Global History?" California Italian Studies, 2(1), 2011.

VAN DER LINDEN, Marcel. "História do Trabalho: O Velho, o Novo e o Global." In: Mundos Do Trabalho. Vol. 1, n 1, 2009, pp. 11-26.

VETTORETTI, Arnadio. História de Tubarão: das origens ao século XX. Tubarão: Prefeitura Municipal, 1992.

VIOTTI DA COSTA, Emília. "Política de terras no Brasil e nos Estados Unidos". In: Da Monarquia à República. São Paulo: Editora Brasiliense, 1985.

\section{Notas de autoria}

Flávia Paula Darossi é doutoranda do Programa de Pós-Graduação em História da Universidade Federal de Santa Catarina e bolsista Capes. Pesquisa regimes e direitos de propriedade em Santa Catarina-Brasil no século XIX. E-mail: flavia.darossi@gmail.com.

Como citar esse artigo de acordo com as normas da revista

DAROSSI, Flávia Paula. Nacionalidade e cidadania pelo acesso à terra no século XIX: reflexões a partir das variações de escalas e da História Global. Sæculum - Revista de História, v. 24, nº 41, p. 124-143, 2019.

\section{Contribuição de autoria}

Não se aplica.

\section{Consentimento de uso de imagem}

Não se aplica.

\section{Aprovação de comitê de ética em pesquisa}

Não se aplica.

\section{Financiamento}

O presente trabalho foi realizado com apoio da Coordenação de Aperfeiçoamento de Pessoal de Nível Superior - Brasil (CAPES) - Código de Financiamento 001.

\section{Licença de uso}

Este artigo está licenciado sob a Licença Creative Commons CC-BY. Com essa licença você pode compartilhar, adaptar, criar para qualquer fim, desde que atribua a autoria da obra.

\section{Histórico}

Recebido em 13/08/2019.

Aprovado em 29/08/2019. 